\title{
Elimination kinetics of synthetic interferon inducer tilorone in experimental animals
}

\author{
Maksym Żuk', Svetlana K. Sumriy², Olga V. Zhuk ${ }^{3}$ \\ ${ }^{1}$ Opole Medical School, Opole, Poland \\ ${ }^{2}$ Department of Biology, Odessa National University, Odessa, Ukraine \\ ${ }^{3}$ Department of Biotechnology and Molecular Biology, University of Opole, Poland
}

Żuk M, Sumriy SK, Zhuk OV. Elimination kinetics of synthetic interferon inducer tilorone in experimental animals. J Pre-Clin Clin Res. 2017; 11(2): 127-131. doi: 10.26444/jpccr/81165

\begin{abstract}
Objective. A comparative investigation was carried out on the kinetics of $\left[{ }^{3} \mathrm{H}\right]$-tilorone $\left(\left[{ }^{3} \mathrm{H}\right]-\mathrm{I}\right)$ excretion in rats and mice. Materials and method. Kinetics of urinary and biliary excretion of [ $\left.{ }^{3} \mathrm{H}\right]-\mathrm{I}$ in rats and mice was studied following a single oral and intravenous administration. The excretion mass balance was monitored in the faeces and urine of rats and mice for 5 and 10 days, respectively. Radioactivity was determined in the samples of excreta using a liquid scintillation counter. Results. In rats, $\left[{ }^{3} \mathrm{H}\right]-$ I were nearly fully $(\sim 80 \%)$ eliminated with excreta in 5 days, indicating a lack of any significant accumulation of the drug in the body. Faecal excretion of tilorone predominated $(69.0 \% \pm 2.8 \%)$, while the elimination in urine was less significant $(9.8 \% 8 \pm 1.2 \%)$. A different pattern of elimination kinetics was observed in mice as excretion proceeded with equal efficiency in urine (27.85-28.9\%) and faeces (26.45-24.4\%), regardless of the route of administration of the substance and at a substantially slower rate compared to rats: only $57.35-52.68 \%$ of total radioactivity was eliminated over 10 days following oral and intravenous administration of tilorone, respectively. MRT of tilorone in rats was $36 \mathrm{~h}$ and in mice 120-150 h.

Conclusion. Parameters for the excretion of tilorone showed significant differences between the 2 groups of animals. Using the example of tilorone excretion kinetics validates the presented novel modified approach to determine the mean residence time (MRT) and amount of drug eliminated from the body during an infinitely long experimental period. This approach can be generally applied for interpretation of nonlinear elimination kinetics of xenobiotics.
\end{abstract}

\section{Key words}

pharmacokinetics, excretion, tilorone, modeling

\section{INTRODUCTION}

Tilorone (trade name Amixin IC) is a broad-spectrum antiviral drug with a polymodal mechanism of action that includes direct inhibition of viral replication in infected cells and stimulation of interferon production [1-6]. It is one of the first effective low molecular weight interferon inducers with anticancer activity [7-9]. Numerous studies have demonstrated the efficacy of tilorone in treating many viral infections, as well as conditions accompanied by weakened immune system defences [10-12]. Tilorone pharmacokinetics have not been extensively studied. The first such study that addressed the distribution of tilorone in mice at a single time point following oral administration was published in 1973 [1,13]. The authors of the presented study have recently published a more detailed study of the metabolism and distribution of tilorone after intravenous and oral administration in mice, which demonstrated that tilorone does not undergo significant biotransformation in the body $[14,15]$. The absolute bioavailability of tilorone amounted to circa $70 \%$ following oral administration, as $21 \%$ of the administered drug underwent pre-systemic elimination in the liver. The pulmonary first-pass effect was observed after intravenous injection of tilorone [15]. The equilibrium distribution ratio of substance between a tissue and blood was higher than unity, indicating the rapid distribution of

Addres for correspondence: Maksym Żuk, Opole Medical School, Opole, Poland, W. Sikorskiego, 7, 45-051 Opole, Poland

E-mail: zhukmaksym@gmail.com

Received: 8 August 2017; accepted: 12 December 2017 tilorone into organ tissues. Irreversible binding of $1-2 \%$ of the total administered drug by the spleen was also noted [15]. Golovenko et al. studied the distribution of the total radioactivity after multiple oral doses of $\left[{ }^{3} \mathrm{H}\right]$-tilorone [16]. A high concentration of the drug in mice over 10 days of the experiment and a slow rate of elimination was shown.

The aim of this investigation was to study $\left[{ }^{3} \mathrm{H}\right]$-tilorone excretion in mice and rats following a single administration of the drug.

\section{MATERIALS AND METHOD}

This study used labeled 2,7-bis-[2-N,N-diethylamino- $\left[{ }^{3} \mathrm{H}\right]-$ ethoxy]-fluorene-9-one dihydrochloride (tilirone, I) (JSC Interkhim, Odessa, Ukraine). The high radiochemical purity of $\left[{ }^{3} \mathrm{H}\right]$ - I (99.6\%) was inferred from radiochromatographic analysis and the specific radioactivity was $2.3 \mathrm{Ci} / \mathrm{mol}$.

The animals were obtained from the breeding facility of the Odessa State Medical University (Odessa, Ukraine). The experiments were performed on female outbred mice ( $\mathrm{n}=8$, per group) weighing $18-24 \mathrm{~g}$ and female Wistar rats $(\mathrm{n}=6)$ 9-11 weeks old, weighing 200-250 g. All animals received a standard laboratory diet and water ad libitum. The experimental animals were kept under a continuous $12 \mathrm{~h}$ light-dark cycle at room temperature.

Experimental protocols were approved by the Ethics Committee of the Pharmacological Committee of Ukraine, carried out in strict accordance with the Ethics Committee regulations for the use of experimental animals; experimental 
protocols were approved by the Ethics Committee of the Department of Biology, Odessa National University.

Two routes of administration of the examined compounds, i.e., oral and intravenous, were used in the study of tilorone excretion in mice. An isotonic solution of $\left[{ }^{3} \mathrm{H}\right]$-tilorone was administered to the eighth mice intravenously via the tail vein (with a $28-\mathrm{G}$ needle) at a dose of $50 \mathrm{mg} / \mathrm{kg}$.

Six rats and 8 mice were administered with $\left[{ }^{3} \mathrm{H}\right]-\mathrm{I}$ at a dose of $50 \mathrm{mg} / \mathrm{kg}$ by oral gavage. The dosing volume was $10 \mathrm{ml} / \mathrm{kg}$ for the mouse and $20 \mathrm{ml} / \mathrm{kg}$ for the rat. The oral dose was dissolved in an isotonic solution. Following gavage, the rat and mice were housed individually in metabolism cages (Tecniplast, Varese, Italy) with free access to food and water throughout the experiments. Urine and faeces samples were collected daily from rats and mice for 5 and 10 days postdosing, respectively (this time period was chosen because previous studies have shown a slow speed of the process of elimination of tilorones in the mice) [15]. Urine volume was measured, and samples were stored at $-18^{\circ} \mathrm{C}$ until analysis. Faeces were air-dried, weighed, and ground to a fine powder before dissolving. About $100 \mathrm{mg}$ nanopure was added to the sample of formic acid ( $2 \mathrm{ml})$, and the mixture was left in the shaker for $24 \mathrm{~h}$ until thorough dissolution.

Radioactivity was determined in the samples of excreta using a Tri Carb 2700 liquid scintillation counter (Canberra Packard, USA).

Pharmacokinetic analysis. The following pharmacokinetic parameters were calculated for tilorone: elimination rate constant $\left(k_{\mathrm{el}}\right)$, half-life in elimination phase $\left(t_{1 / 2}\right)$, MRT, and the amount of drug eliminated from the body over an infinitely long experimental period $\left(A_{0-\infty}\right)$; in order to determine such fractional elimination parameters, regression analysis by a modified "rate-quantity" method was utilized, described in earlier studies [17], and using validated software PKSolver [18]. This was based on the use of the integrated analog of the basic equation of the method and its further transformation to adapt to reproof poly exponential kinetics of xenobiotics excretion. This enabled determination of the total quantity of the drug eliminated from the body in conditions of infinite exposure $\left(A_{0-\infty}\right)$ and the constant elimination $\left(k_{e l}\right)$ using regression analysis on the basis of the following equations:

and for $M R T$

$$
\frac{A_{0-t}}{t} \approx A_{0-\infty} \cdot k_{e l}-k_{e l}\left(\frac{\int_{0}^{t} A_{0-t} \cdot d t}{t}\right),
$$

$$
\left(1-\left(A_{0-t} / A_{0-\infty}\right)\right) / k_{e l} \approx M R T-\left(t-\left(\int_{0}^{t} A_{0-t} \cdot d t / A_{0-\infty}\right)\right)
$$

Equation (2) suggests that at the same time interval, the values of $\left(1-\left(A_{0-t} / A_{0-\infty}\right)\right) / k_{t}$ are distributed linearly concerning values of $\left(t-\left(\int_{0}^{t} A_{0-t} / A_{0-\infty}\right)\right)$. Then, the regression curve has a tangent angle that equals one and crosses the ordinate and the abscissa in the point equal to $\left(1-\left(A_{0-t} / A_{0-\infty}\right)\right) / k_{e l}$ and $\left(t-\left(\int_{0}^{t} A_{0-t} / A_{0-\infty}\right)\right)$, equal to the
value of MRT.
Statistical analysis. All average values are given as mean \pm SD. Values of total radioactivity in excretes of mice and rats were compiled with the Student's $t$-test for unpaired data. The acceptable probability for a significant difference was $p<0.05$.

\section{RESULTS}

Elimination of $\left[{ }^{3} \mathrm{H}\right]$-tilorone in rats. In rats, almost $80 \%$ of $\left[{ }^{3} \mathrm{H}\right]$ total radioactivity was excreted in faeces and urine over the course of $120 \mathrm{~h}$ postdose. The principal route of tilorone elimination in rats was faecal, as it mediated excretion of about $69 \%$ of the total administered dose during the first 5 days after administration of the drug.

Urinary excretion in rats was a steady-state process characterized by a slow elimination rate. In the first $120 \mathrm{~h}$ postdose, $10 \%$ of the total administered dose was eliminated via the renal route. The efficiency of $\left[{ }^{3} \mathrm{H}\right]$-tilorone excretion in faeces was 7-fold higher than in urine in rats (Fig. 1); thus, overall elimination is mainly determined by the parameters of faecal excretion. The maximum radioactivity elimination rate from the body was observed in the first $72 \mathrm{~h}$ post-dose.

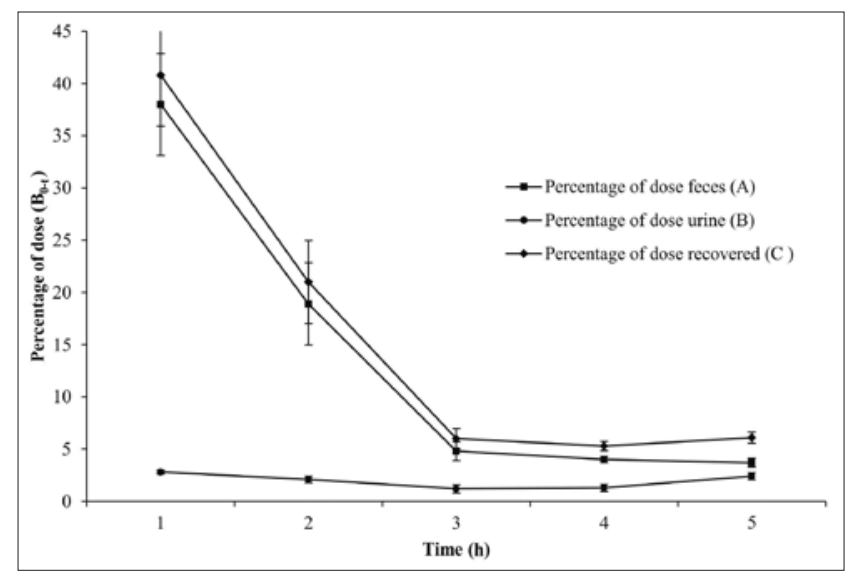

Figure 1. Elimination of the total radioactive material (\% of the administered dose) in excretes of rats after a single administration of $\left[{ }^{3} \mathrm{H}\right]$-tilorone at a dose of $50 \mathrm{mg} / \mathrm{kg}$. The data represent mean $\pm S D, n=6$

Overall elimination and faecal excretion in particular were biphasic with a rapid phase $(0-72 \mathrm{~h})$ responsible for elimination of $62-68 \%$ of the drug and slow phase $(72-120 \mathrm{~h}$ ) mediating excretion of $8-11 \%$ of the total administered dose. The urinary elimination rate was slow and mono-exponential throughout the whole period of the study.

The kinetics of the overall elimination and faecal excretion in rats could be described by a classic 2-compartment model. Corresponding kinetic parameters are given in Tab. 1. Elimination half-time was $21 \mathrm{~h}$ post-dose in the rapid phase, while the remaining radioactivity $(\sim 4-7 \%$ of the total administered dose) had a longer elimination halflife of about $150 \mathrm{~h}$.

Elimination of $\left[{ }^{3} \mathrm{H}\right]$-tilorone in mice. A characteristic feature of tilorone metabolism in mice was a slower elimination rate compared to rats, as only $57.35 \%$ of the oral administered dose was eliminated in total within 10 days. Also, in contrast to observations in rats, the efficacy of excretion in urine and faeces was similar: $27.85 \%$ and $26.45 \%$ of the administered oral dose, respectively (Tab. 2). Elimination kinetics in urine 
Table 1. Kinetic parameters for elimination of total radioactive material (\% of dose) in excretes of rats after a single administration of $\left[{ }^{3} \mathrm{H}\right]-\mathrm{I}(50 \mathrm{mg} /$ $\mathrm{kg})$ in the fast (24-72 h) and slow phases (72-120 h) of the experiment

\begin{tabular}{lcccc}
\hline Parameters & \multicolumn{2}{c}{ Percentage of dose: faeces } & \multicolumn{2}{c}{ Percentage of dose recovered } \\
\cline { 2 - 5 } & $\begin{array}{c}\text { fast phase } \\
(24-72 \mathrm{~h})\end{array}$ & $\begin{array}{c}\text { slow phase } \\
(72-120 \mathrm{~h})\end{array}$ & $\begin{array}{c}\text { fast phase } \\
(24-72 \mathrm{~h})\end{array}$ & $\begin{array}{c}\text { slow phase } \\
(72-120 \mathrm{~h})\end{array}$ \\
\hline $\mathrm{k}_{\mathrm{el}}\left(\mathrm{h}^{-1}\right)$ & $-0.035 \pm 0.009$ & $-0.0052 \pm 0.0002$ & $-0.0328 \pm 0.004$ & $-0.0048 \pm 0.0002$ \\
\hline $\mathrm{T}_{0,5}(\mathrm{~h})$ & $19.7 \pm 3.67$ & $133.3 \pm 12.43$ & $21.1 \pm 5.78$ & $144.4 \pm 14.09$ \\
\hline $\mathrm{C}_{0}(\%$ of dose $)$ & $74.4 \pm 2.45$ & $6.7 \pm 0.98$ & $81.3 \pm 7.12$ & $3.4 \pm 0.78$ \\
\hline
\end{tabular}

Table 2. Elimination of total radioactive material (\% of administered dose) in excretes of mice after a single oral administration of $\left[{ }^{3} \mathrm{H}\right]$-tilorone (50 mg/kg).

\begin{tabular}{lccc}
\hline Time $(\mathrm{h})$ & $\begin{array}{c}\text { Percentage of dose } \\
\text { faeces }(\mathrm{A})\end{array}$ & $\begin{array}{c}\text { Percentage of dose } \\
\text { urine }(\mathrm{B})\end{array}$ & $\begin{array}{c}\text { Percentage of dose } \\
\text { recovered }(\mathrm{C})\end{array}$ \\
\hline 24 & $5.02 \pm 1.04$ & $5.68 \pm 1.38$ & $11.0 \pm 1.73$ \\
\hline 48 & $2.95 \pm 0.44$ & $4.13 \pm 0.69$ & $8.08 \pm 0.82$ \\
\hline 72 & $2.81 \pm 0.31$ & $4.17 \pm 0.24$ & $7.07 \pm 0.39$ \\
\hline 96 & $2.77 \pm 0.69$ & $3.91 \pm 0.47$ & $6.88 \pm 1.83$ \\
\hline 120 & $3.33 \pm 0.64$ & $3.22 \pm 0.57$ & $6.85 \pm 1.86$ \\
\hline 144 & $2.18 \pm 0.59$ & $2.19 \pm 0.23$ & $4.67 \pm 0.63$ \\
\hline 168 & $2.08 \pm 0.32$ & $1.87 \pm 0.19$ & $4.05 \pm 0.37$ \\
\hline 216 & $1.85 \pm 0.41$ & $1.43 \pm 0.15$ & $3.58 \pm 0.44$ \\
\hline 240 & $1.79 \pm 0.42$ & $0.78 \pm 0.19$ & $2.77 \pm 0.46$ \\
\hline
\end{tabular}

1 Percentage of dose also includes cage washes

and faeces were not parallel as the elimination via the renal route was almost 2 -fold higher than in faeces. Regardless of the route of administration of the examined substance, the process of excretion in the urine and faeces in mice is almost equally effective. Average excretion of $\left[{ }^{3} \mathrm{H}\right]-\mathrm{I}$ for a 10 -day period in case of intravenous administration was $28.9 \pm 0.24 \%$ in urine, and in faeces $-24.5 \pm 0.48 \%$ of the administered dose. After $240 \mathrm{~h}$ of substance application, only $52.68 \pm 0.39 \%$ of the administered dose was excreted in urine and faeces (Tab. 3 ).

As equation (1) displays, irrespective of the species (mouse or rat), experimental data are strictly linear in these coordinates (Fig. 2); therefore, parameters of elimination can be determined without decomposition of the kinetic model.

Table 3. Elimination of total radioactive material (\% of administered dose) in excreta of mice after a single intravenous administration of $\left[{ }^{3} \mathrm{H}\right]$ -tilorone $(50 \mathrm{mg} / \mathrm{kg})$.

\begin{tabular}{lccc}
\hline Time $(\mathrm{h})$ & $\begin{array}{c}\text { Percentage of dose } \\
\text { faeces }(\mathrm{A})\end{array}$ & $\begin{array}{c}\text { Percentage of dose } \\
\text { urine }(\mathrm{B})\end{array}$ & $\begin{array}{c}\text { Percentage of dose } \\
\text { recovered }^{\prime}(\mathrm{C})\end{array}$ \\
\hline 24 & $5.50 \pm 2.32$ & $6.30 \pm 1.17$ & $11.90 \pm 2.60$ \\
\hline 48 & $3.10 \pm 0.31$ & $4.20 \pm 0.54$ & $7.38 \pm 0.59$ \\
\hline 72 & $2.61 \pm 0.44$ & $5.31 \pm 0.49$ & $6.17 \pm 0.66$ \\
\hline 96 & $2.51 \pm 0.33$ & $3.60 \pm 0.56$ & $6.22 \pm 0.54$ \\
\hline 120 & $3.03 \pm 0.51$ & $2.62 \pm 0.32$ & $5.78 \pm 0.43$ \\
\hline 144 & $1.81 \pm 0.24$ & $2.32 \pm 0.31$ & $4.27 \pm 0.53$ \\
\hline 168 & $1.63 \pm 0.22$ & $1.80 \pm 0.07$ & $3.45 \pm 0.24$ \\
\hline 216 & $1.45 \pm 0.23$ & $1.23 \pm 0.14$ & $2.78 \pm 0.27$ \\
\hline 240 & $1.40 \pm 0.25$ & $1.02 \pm 0.23$ & $2.47 \pm 0.48$ \\
\hline
\end{tabular}

'Percentage of dose also includes cage washes
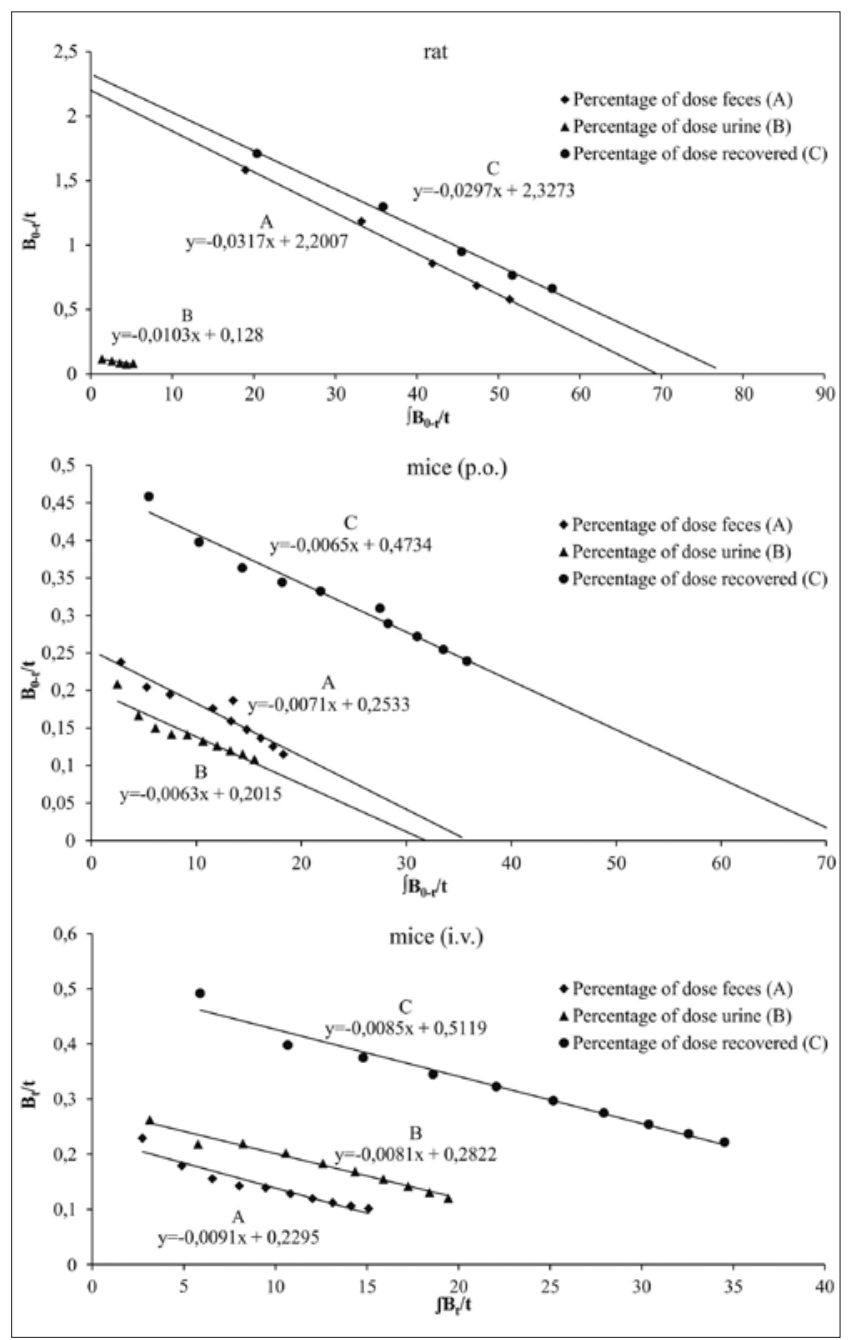

Figure 2. Graphic interpretation of equation (1) based on data on the excretion kinetics of tilorone and metabolites in rat and mice (determination of values $k$ and $\mathrm{B}_{0-\infty}$ using the relationship between $\mathrm{B}_{0-\mathrm{t}} / \mathrm{t}$ and $\mathrm{B}_{\mathrm{o-t}} / \mathrm{t}$ )

The elimination rate of tilorone and its metabolites in rats is significantly dependent on the excretion route: renal $k_{e l}$ value, as determined from the tangent of the slope angle, is 3 times lower than the faecal $k_{e l}$ value. Elimination half-time equaled 22 and 67 h post-dose, respectively. A similar pattern was observed for the total value of eliminated tilorone and its metabolites under infinite exposure $\left(A_{0-\infty}=69 \%\right.$ with faeces and $12 \%$ with urine).

In contrast, the elimination of tilorone in mice under oral administration was nearly identical via the renal and faecal routes, and overall fairly slow (Fig. 2). The half-life of time of elimination $\left(t_{1 / 2}\right)$ in urine was $110 \pm 5.02 \mathrm{~h}$ after oral administration, while after intravenous administration, it was significantly lower $t_{1 / 2}=85.57 \pm 1.88 \mathrm{~h}(p \leq 0.05) . t_{1 / 2}$ in the case of intestinal and hepatic excretion - $97.62 \pm$ 7.85 and $85.57 \pm 3.65 \mathrm{~h}$, respectively. In infinite exposure, the amount of total radioactivity excreted was $32-36 \%$ in the case of oral administration, and $25-35 \%$ in the case of intravenous dosing.

Having determined the values of $k_{\mathrm{el}}$ and $A_{0-\infty}$ by linear regression, it is possible to use them for the calculation of MRT. MRT value can be determined from the crossing point of the plot line with ordinate and abscissa in accordance with Equation 2 (linear anamorphosis using the value of 


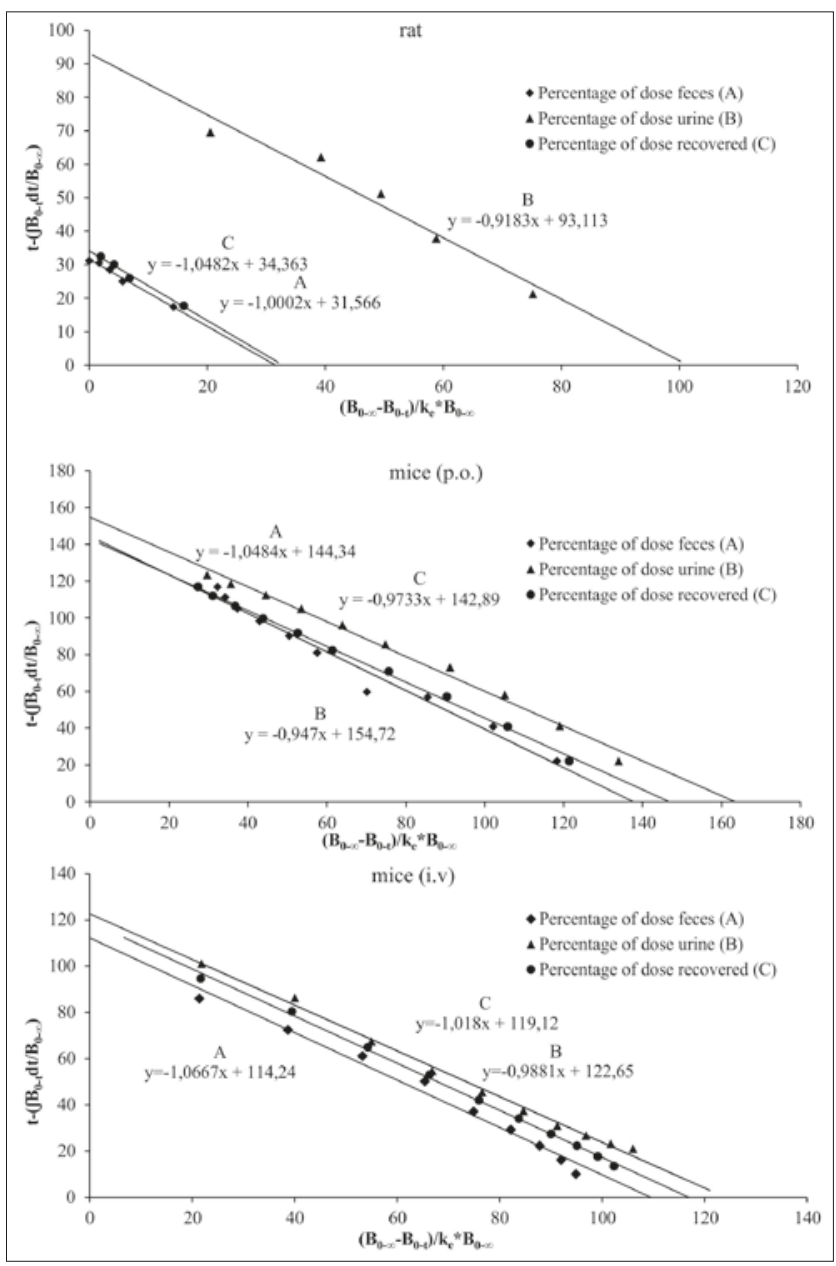

Figure 3. Graphic interpretation of equation (2) - the relationship between $t-\left(\int B_{0-t} d t / B_{0-\infty}\right)$ and $\left(B_{0-\infty}-B_{0-t}\right) /\left(k_{e} B_{0-\infty}\right)$

$t-\left(\int A_{0-t} \mathrm{dt} / A_{0-\infty}\right)$ as ordinate and $\left(A_{0-\infty}-A_{0-t}\right) /\left(k_{\mathrm{e}} A_{0-\infty}\right)$ as abscissa (Fig. 3).

According to this method, the calculated values are presented in Table 4 . The method proposed by the authors allowed highly linearized sets of experimental data to be obtained, as evidenced by the tangent of the slope angle

Table 4. Kinetic parameters for elimination of total radioactive material in excreta of rats and mice after a single administration of $\left[{ }^{3} \mathrm{H}\right]$-tilorone

\begin{tabular}{lll}
\hline Parameters & $\begin{array}{c}\mathrm{B}_{0-\infty} \\
\text { (\% of doses) }\end{array}$ & $\begin{array}{c}\text { MRT } \\
(\mathrm{h})\end{array}$ \\
\cline { 2 - 3 } Rats & Figure 2 & Figure 3 \\
\hline Percentage of dose: urine & $12.8 \pm 2,89$ & $93.1 \pm 4,98$ \\
\hline Percentage of dose: feces & $69.1 \pm 4,32$ & $31.6 \pm 2,78$ \\
\hline Percentage of dose recovered & $78.4 \pm 3,68$ & $34.3 \pm 2,58$ \\
\hline Mice (p.o) & & \\
\hline Percentage of dose: urine & $32.9 \pm 1.79$ & $154.7 \pm 9.76$ \\
\hline Percentage of dose: feces & $34.5 \pm 2.54$ & $144.3 \pm 6.94$ \\
\hline Percentage of dose recovered & $66.8 \pm 5.09$ & $142.9 \pm 8.32$ \\
\hline Mice (i.v.) & & $122.65 \pm 6.22$ \\
\hline Percentage of dose: urine & $34.53 \pm 2.68$ & $114.24 \pm 5.05$ \\
\hline Percentage of dose: feces & $26.21 \pm 2.23$ & $119.12 \pm 7.86$ \\
\hline Percentage of dose recovered & $60.98 \pm 4.98$ & \\
\hline
\end{tabular}

equal to unity in Figure 3. MRT values were $140-150$ h in mice, reflecting a slower elimination rate. Only $66 \%$ of the oral administered drug was excreted in conditions of infinite exposure. Intravenous $\left[{ }^{3} \mathrm{H}\right]$-I administration to mice caused an insignificant but a reliable $(p \leq 0.05)$ change in the MRT value, which was $110-124 \mathrm{~h}, A_{0-\infty}$ " $61 \%$.

\section{DISCUSSION}

This paper presents the comparative examination of the process of tilorone excretion in rats and mice after a single administration (oral and intravenous). Significant differences were demonstrated in the effectiveness of the excretion processes in urine and faeces in the experimental animals. Faecal elimination in rats is of a 2-phase character constituted $69 \%$ of the administered dose, whereas the process of excretion in urine (about 10\%) was stationary during the whole period of examination. During 5 days of the experiment, almost the entire administered dose was excreted from the rat's organism ( $90 \%)$ (Tab. 1,4$)$. In the case of mice, irrespective of the route of administration of $\left[{ }^{3} \mathrm{H}\right]-\mathrm{I}$, a slow elimination process was observed in the organism, and mathematical calculations demonstrated that only $60 \%$ of the administered dose in an infinite exposition was excreted from the organism of the examined animals. On examination of the distribution processes, it was inferred that the process of irreversible binding to the spleen may explain the extremely slow excretion in urine and faeces and that only $70 \%$ of the administered dose is eliminated in case of infinite exposure. It is interesting to note that the route of administration of $\left[{ }^{3} \mathrm{H}\right]$-I to mice has an insignificant effect on the kinetic parameters of excretion - the amount of excreted drug was the same, and the elimination process rate after intravenous administration insignificantly higher. Previous studies on tilorone metabolism by the authors of this study showed that this drug undergoes little biotransformation in rodents $[13,15,19$,$] . Around 89 \%$ of the drug is eliminated in its original, parent compound form in the faeces of rats and mice. Two minor metabolites resulting from oxidation of aliphatic ends of the tilorone molecule were observed in urine $[14,19]$.

The presented data show no significant differences in metabolic processes of tilorone in rats and mice, and the data give no grounds for explaining the differences in the process of its excretion.

Currently, the literature does not provide any research data concerning the processes of tilorone distribution in rats, leading to no possibility of an evaluation of the relationship between these processes and the processes of the excretion of the examined substance. Perhaps the results of future studies of tilorone distribution in rats will help explain the differences in the kinetics of tilorone elimination from the rats and mice.

MRT calculation using multi-compartmental models or models in which processes with various constant rates may be distinguished is very complex; therefore, a new mathematical model based on non-compartmental modeling and regression analysis was applied that allowed the precise calculation of the examined parameters. MRT calculations in accordance with the software PKSolver showed comparable values with the parameters calculated using the authors' proposed modification of the 'rate-quantity' method (Tab. 4). 
Therefore, for rats, MRT is equal to $47.6 \mathrm{~h}$ (dose recovered), and MRT for mice is equal to $106.34 \mathrm{~h}$ and $151.34 \mathrm{~h}$ under i.v. and p.o. administration, respectively. Novel mathematical approaches that allowed efficient calculation of elimination parameters in this study may, therefore, be useful for the analysis of the poly-exponential kinetics of drug.

\section{Declaration of Interest}

The authors declare that they have no conflicts of interest. The authors alone are responsible for the content and writing of this article.

\section{REFERENCES}

1. Chandra P, Wright GJ. Tilorone hydrochloride: the drug profile. Top Curr Chem. 1977; 72: 125-126.

2. Ershov FI. Amixin application in the therapy of acute and chronic viral infections. Moscow: Medicine; 1998.

3. Hiyama Y, Kuriyama K. Dissociation between antiinflammatory action of tilorone and its interferon inducing activity. Agents Actions, 1991; 33: 229-232.

4. Koval'chuk AV, Borisevich SV, Syromiatnikova SI, et al. Antiviral activity of an interferon inducer amixin in experimental West Nile Fever. Vopr Virusol. 2004; 49(2): 8-11, Russian.

5. Kremerman IB, Prijmiagi LS, Ershov FI. Experimental study of the interferonogenic and antiviral activity of biologically active substances. Vopr Virusol. 1984; 29(5): 549-553, Russian.

6. Liakhov SA, Litvinova LA, Andronati SA et al. Biochemical mechanisms of realization of antiviral and interferon-inducing activity of amixine and its analogs. Ukr Biokhim Zh. 2001; 73(4): 108-113, Russian.

7. Basley WA, Rees RC, Greager JA, Baldwin RW. Antitumour effects of tilorone hydrochloride on the in vivo growth of chemically induced and spontaneously arising rat tumours. Chemotherapy, 1981; 27: 44-47.

8. Zhou D, Tuo W, Hu H, el al. Synthesis and activity evaluation of tilorone analogs as potential anticancer agents. Eur J Med Chem. 2013; 64: $432-441$
9. Skrots'ka OI, Zholobak NM, Antonenko SV, Spivak MIa, Karpov OV. Antiherpetic effect of RNA-tilorone molecular complex in cell culture. Mikrobiol Z. 2007; 69(3): 62-68. Ukrainian.

10. Anderson AL, Banks KE, Pontoglio M, Yaniv M, McLachlan A. Alpha/ beta interferon differentially modulates the clearance of cytoplasmic encapsidated replication intermediates and nuclear covalently closed circular hepatitis B virus (HBV) DNA from the livers of hepatocyte nuclear factor lalpha-null HBV transgenic mice. J Virol. 2005; 79(17): 11045-11052.

11. Semenenko TA, Selkova EP, Nikitina GY et al. Immunomodulators in the prevention of acute respiratory viral infections. Russian Journal Immunology 2002; 7: 105-114.

12. Sokolova TM, Uryvaev LV, Tazulakhova EB, Ershov FI, Malyshenkova IK, Didkovskil NA. Individual changes of gene expression in the interferon system in human blood cells due to amixin and cycloferon. Vopr Virusol. 2005; 50(2): 32-36, Russian.

13. Gaur V, Chandra P. Subcellular distribution of ${ }^{14} \mathrm{C}$-tilorine hydrochloride in tissues of mice and rats. Naturwissenschaften, 1973; 60: 263.

14. Zhuk OV, Maltsev GV, Sumriy SK. The synthesis and pharmacokinetics of ${ }^{3} \mathrm{H}$-amixin, a low molecular weight synthetic interferon inductor, in experimental animals. Drug of the Future, 2002; 27(Supp 1): 549.

15. Zinkovsky VG, Zhuk OV, Sumriy SK. Pharmacokinetic of a synthetic interferon inducer amixin in mice. Pharmacol Rep. 2007; 59. 739-751.

16. Golovenko NY, Borisyuk IY. Pharmacokinetics of amixin after repeated peroral administration to mice. Bull Exp Biol Med. 2005; 140(6): 708 710 .

17. Zinkovsky VG, Zhuk OV. Estimation of the characteristic residence time and excretion parameters of xenobiotic in cocase of the its multicompartment distribution. Proceeding of the 14-th National Conference on Applications of Mathematics in Biology and Medicine, 2008; 140-145.

18. Zhang Y, Huo M, Zhou J, Xie S (2010) PKSolver: An add-in program for pharmacokinetic and pharmacodynamics data analysis in Microsoft Excel. Comput Methods Programs Biomed. 99(3):306-14. doi: 10.1016/j. cmpb.2010.01.007.

19. Karpinchik VA, Maltsev GV, Sumriy SK. Synthesis of amixin- ${ }^{3} \mathrm{H}_{2}$ and methods to extract amixin from biological material. Khim Farm Zh. 2002; 8: 47-49. Russian. 